\title{
Carving Nature at its Inherent Joints: The Problem of the Independent Criterion
}

\author{
Sam Page \\ Concordia College
}

Abstract: Individuative Realism is the thesis that reality is individuated intrinsically -that is, that there exist some objects and/or kinds of objects that are circumscribed by boundaries that are totally independent of our gerrymandering. If this thesis is true, then how do we determine which individuation schemes cut reality at its inherent joints? Since our individuation schemes cannot be compared directly with the way reality is individuated intrinsically without begging the question about the latter, some philosophers argue that a match can only be determined indirectly, in virtue of an independent criterion. This paper considers a few proposed independent criteria and finds them wanting. The paper concludes by suggesting that such an independent criterion is unattainable in principle.

\section{Introduction}

A metaphysical thesis which enjoys sustained interest among philosophers is that reality is individuated intrinsically-that is, that there exist some objects and/or kinds of objects that are circumscribed by boundaries wholly independent of where we draw the lines. Though this thesis is often labeled 'Metaphysical Realism', the label has come to signify a variety of positions, and is thereby worth avoiding. So let us give the aforementioned thesis a new name: Individuative Realism. The claim is that the natural world is individuated on its own, irrespective of our carving schemes. 
If it is true that reality is individuated intrinsically, then we might want to know how reality is individuated intrinsically - that is, what the objects are into which reality is ultimately divided. For instance, is a bunch of ten bananas ultimately one thing, or ten things, or millions of things (corresponding to the number of atoms comprising the bunch)? The Individuative Realist wants to know. A 'direct' strategy for determining how reality is individuated intrinsically is simply to carve into reality and see where the inherent joints actually are-that is, to go hunting for crisp, unambiguous boundaries. The primary problem with the direct approach is that the closer individual objects are examined, the blurrier their boundaries appear, and the bizarre entities at the quantum level might not even be individuatable. In addition to these practical problems, there looms a perhaps larger theoretical problem for the direct approach. Even if objects with razor sharp boundaries were discovered, there is the epistemological problem of verifying that they are the inherently natural objects, rather than amalgamations of smaller, albeit more inherently natural, objects. It would seem that any individuation scheme could always admit of finer individuation. How might one adjudicate between the various permutations of individuation schemes?

The Individuative Realist aspires to find a match between our individuation schemes and the way reality is individuated intrinsically; but this cannot simply be a matter of comparing the two sides, since one of the sides-how reality is individuated intrinsically -is not known antecedently. The challenge faced by the Individuative Realist seems analogous to the challenge of finding a match between a key and keyhole. It is not possible to determine a match between key and keyhole by visually comparing the two, because the inside of the keyhole is not visible. Rather, a match is best determined indirectly, by looking for something else which signifies a match-namely, the unlatching of the lock. The unlatching of the lock is an independent criterion for determining a match between key and keyhole. If a key is inserted into the keyhole, and the lock opens, then the key matches the keyhole. Some philosophers think that a match between our individuation schemes and the way reality is individuated intrinsically

'For an analysis of the 'direct' strategy and its challenges see Sam Page, "The Challenge of Observing Reality's Inherent Joints", Kriterion, no. 20 (2006), pp. 22-28. 
can also only be determined indirectly, by appeal to an independent criterion, rather than by direct comparison.

As another example, imagine that people disagree about the length of something. How could their rival measurements be adjudicated? By consulting an independent, objective standard, which in this case would be a measuring device of some kind. A measuring device, such as a meter stick or tape measure, is an independent criterion for determining length. It is an 'independent' criterion (or 'objective' standard) because it is independent of our subjective judgments. Now, is there an independent criterion for determining which of our individuation schemes cut reality at its inherent joints?

This paper critically considers the indirect approach for determining how reality is individuated intrinsically by examining a few proposals for independent criteria. One account, covered in Part A, is that reality is ultimately individuated by elite properties. According to this account, knowledge of certain elite properties can get us to knowledge of reality's inherent joints. A second account, discussed in Part $B$, involves an abductive inference from the success of science. According to this account, there is reason to think that the individuation schemes of the natural sciences correspond to the way reality is individuated intrinsically, because such a correspondence could explain the success of natural science. A third account, considered in Part $\mathrm{C}$, involves the confirmation of theory by data. According to this account, given rival individuation schemes, empirical observation can confirm which scheme is reality's own, or at least disconfirm those that are not. I argue that these particular strategies are wanting, and suggest in Part D that no independent criterion is available in principle.

\section{Part A: Individuation-Defining Properties}

\section{Natural Properties}

One indirect strategy for Individuative Realism involves the thesis that certain elite properties determine the objects into which reality is individuated intrinsically. If we can find these properties, so the story goes, then reality's inherent joints will follow. We can approach this thesis by agreeing that there are many objects in the world, such as 
bears, mountains, and molecules, and many properties too, such as the properties of being red, hot, or slippery. One factor that distinguishes clearly distinguishable things, such as bears and mountains, is that they do not share salient properties. Whereas bears have the properties of being alive, mobile, and weighing less than one ton, mountains have the properties of being inanimate, immobile, and weighing thousands of tons. Properties do indeed distinguish natural things. What complicates matters is that reality can be individuated variously depending on which properties are privileged. As an illustration, imagine a world consisting of ten objects: $0,1,2,3,4,5,6,7,8$, and 9 . There are many ways to classify these objects. There is the set of objects with the property 'pointed': $\{1,2,3,4,5,6,7,9\}$. There is the set of objects bearing the property 'symmetrical when cut horizontally in half: $\{0,3,8\}$. There is the set of objects with the property 'symmetrical when cut vertically in half': $\{0,8\}$. There is the set of objects with the property 'encloses a space': $\{0,4,6,8,9\}$. And so on ad infinitum.

Regarding the abundance of properties, David Lewis writes: "Properties carve reality at the joints-and everywhere else as well." "Among all the countless things and classes that there are," Lewis writes, "most are miscellaneous, gerrymandered, ill-demarcated." However, Lewis maintains that "an elite minority [of things and classes] are carved at the joints". ${ }^{4}$ Now the crucial question: Which objects and/or kinds of objects have inherently natural boundaries? One strategy for answering this question is suggested (though perhaps not ultimately defended) by Lewis, which is that reality's inherent individuation scheme is established by "an elite minority of special properties" which he calls "natural properties." There is, according to Lewis, "an objective difference between natural and unnatural properties", though it "admits of degree." The hope, at least as far as the Individuative Realist is concerned, is that the way reality is

${ }^{2}$ David Lewis, "New Work for a Theory of Universals", Australasian Journal of Philosophy, vol. 61, no. 4 (December 1983), p. 346.

${ }^{3}$ David Lewis, "Putnam's Paradox", Australasian Journal of Philosophy, vol. 62, no. 3 (September 1984), p. 227.

${ }^{4}$ Lewis, "Putnam's Paradox", p. 227.

${ }^{5}$ Lewis, "New Work for a Theory of Universals", p. 346. See also p. 371. See also "Putnam's Paradox", p. 227.

${ }^{6}$ Lewis, "New Work for a Theory of Universals", p. 347. 
individuated intrinsically falls out of the distribution of natural properties. The former is a function of the latter. Lewis emphasizes that it is not the case that natural properties are natural because they are privileged by us, or in his words, "that we confer naturalness on properties when we happen to take an interest in them." If that were the case, then the naturalness of natural properties would be a function of something about us-and thus they would not be inherently natural. Rather, what makes properties natural has to be something about the intrinsic nature of reality.

So what are the natural properties? Lewis does not provide a process for determining this, but instead defers to experts capable of making the discriminations: "[P]hysics discovers properties. And not just any properties-natural properties." ${ }^{8}$ Lewis elaborates:

To a physicalist like myself, the most plausible inegalitarianism seems to be the one that gives a special elite status to the 'fundamental physical properties': mass, charge, quark color and flavour, .... (It is up to physics to discover these properties, and name them; physicalists will think that present-day physics at least comes close to providing a correct and complete list.) (... Indeed, physics discovers which things and classes are the most elite of all. ${ }^{9}$

According to this view, the fundamental properties discovered by physics delimit the things and kinds of things into which reality is individuated intrinsically.

\section{The Paradox}

According to Catherine Elgin, the claim that physicists discover natural properties breeds a famous paradox:

Lewis's conviction that the naturalness of properties is independent of and antecedent to scientific inquiry recalls the Euthyphro problem. (. . .) Does science favor particular properties because they are natural, or are they natural because science favors them. ${ }^{10}$

\footnotetext{
${ }^{7}$ Lewis, "New Work for a Theory of Universals", p. 377.

${ }^{8}$ Lewis, "New Work for a Theory of Universals", p. 365.

${ }^{9}$ Lewis, "Putnam's Paradox", p. 228.

${ }^{10}$ Catherine Z. Elgin, "Unnatural Science", The Journal of Philosophy, vol. 92,
} 
If science favors certain properties because those properties are natural, then it still remains to be shown that those properties are natural. Put rhetorically, In virtue of what are the properties reputed to be natural 'natural'? The answer cannot be that it is in virtue of the fact that science favors them, because then we are back to the question, Does science favor particular properties because they are natural, or are they natural because science favors them? Rather, the answer must be in virtue of something about the intrinsic nature of reality.

In a recent article, Mary Kate McGowan critically considers the possibility that there is a "single objective way that the world is," which is "entirely independent of us," and which is determined by something equivalent to Lewis' natural properties, called "base structure-defining properties" by McGowan." McGowan articulates the challenge to this thesis as follows:

In virtue of what is a structure-defining property structure defining-us or the world? The [Individuative Realist] maintains that the structure-defining status of properties is an entirely objective matter while the non-realist maintains instead that we somehow make a property structure-defining. ${ }^{12}$

The crux, as McGowan puts it above, is explaining how "the structure-defining status of properties is an entirely objective matter".

McGowan explicates an account of natural properties which appeals to the hierarchical series of connections between supervenient and base properties. ${ }^{13}$ According to this account, every higher level property supervenes, either directly or indirectly, on a base, structural level. This is just to say that there cannot be a physical change in a higher level without a corresponding change in the lower level upon which that higher level supervenes. Though there are

no. 6 (June 1995), p. 299.

"Mary Kate McGowan, "The Neglected Controversy Over Metaphysical Realism", Philosophy 77 (January 2002), pp. 14-16.

${ }^{12}$ McGowan, "The Neglected Controversy Over Metaphysical Realism", p. 7. I have replaced her 'Metaphysical Realism' with 'Individuative Realism', since the positions seem to be equivalent.

${ }^{13}$ This is a strategy that Lewis suggests, but does not develop, in "Putnam's Paradox", p. 228. 
many property levels, each supervening on the one below, they all bottom out on this base level. For example, the property of being a piece of wood supervenes on lower-level molecular structure, which in turn supervenes on lower-level atomic structure, and so on down to the base structure-defining properties (whatever they are). This base determines the "single objective way that the world is", and permits "(the possibility of) a single correct description of the world. The description that accurately describes the unique-ish base is ultimately correct in virtue of accurately describing the world in its utmost detail." ${ }^{14}$ Such a description could cut reality at its inherent joints.

Even if the supervenience model is accurate-that is, even if there are supervening property levels, such that there cannot be a physical change in a higher level without a corresponding change in the lower level-it is not clear that it would help the Individuative Realist. As McGowan points out, the promise of this strategy rests on the assumption that the world is finitely complex. If the world is infinitely complex, then there is no end to the supervenience, and thus no base level. But even if the world is finitely complex, and there are base structure-defining properties, it is unclear how to isolate them. There could, unbeknownst to us, always be a lower level of structure-defining properties upon which any ostensibly lowest level supervenes. Thus, even if the base level is attainable, it could still be unknowable as such. As McGowan puts it, "one might argue against [Individuative Realism] on the grounds that an objective but ultimately unknowable world is not worth presupposing in the first place."15

\section{Conclusion to Part $A$}

The natural property account maintains that some objects and/ or kinds of objects are inherently natural in virtue of their being a function of certain elite properties. The primary objection to this back door route to the individuation inherent in nature is that it just seems to shift the burden of proof back a step. How do we know how reality is individuated intrinsically? It is a function of natural

${ }^{14}$ McGowan, "The Neglected Controversy Over Metaphysical Realism", p. 16. ${ }^{15}$ McGowan, "The Neglected Controversy Over Metaphysical Realism", p. 17. 
properties. An analogous dialectic runs as follows. God exists. How do I know? An angel told me. Though natural properties could conceivably account for one mystery (how reality is individuated intrinsically), they are themselves another mystery. Elgin draws a stronger conclusion which provides a nice segue into part B:

Nothing confers naturalness on properties but their contribution to successful science. Properties are natural, then, only because natural science favors them. Naturalness of properties is an output of successful inquiry, not an input into it. ${ }^{16}$

Contrary to Elgin, could it be that the success of science provides reason to think that the individuation science recognizes corresponds to inherently natural divisions? The next part considers this possibility.

\section{Part B: Explaining the Success of Science}

The Abductive Inference

Another indirect strategy for Individuative Realism involves an abductive inference. According to the argument, (A) a correspondence between (1) the individuation schemes of the natural sciences and (2) the way reality is individuated intrinsically, could explain (B) the astonishing success of science. That (A), which is inferred, could explain (B), which seems in need of explaining, is what makes (A) a plausible inference. The promise of this abductive inference is that explanatory efficacy entails truth, as it often does. The inferred truth is that the individuation schemes of science correspond to the way reality is individuated intrinsically.

There are pitfalls in the use and interpretation of this argument that need to be avoided before a proper assessment can take place. These pitfalls involve (1) the role of the 'because' and (2) the construal of 'success'. Regarding (1), consider a statement resembling an abductive argument: Ether puts people to sleep because it has dormitive power. The statement seems explanatory since something happens (ether puts people to sleep) because of something else (ether has dormitive power). However, the latter merely

${ }^{16}$ Elgin, "Unnatural Science", p. 300. 
qualifies (or paraphrases) the former, rather than explains it. To say 'ether has dormitive power' is just to say 'ether puts people to sleep'. It is important that the inference supporting Individuative Realism is actually explanatory, and not merely qualificatory, since it is the promise of explanatory efficacy that makes the inference compelling in the first place. The statement 'natural science has been successful because its individuation schemes correspond to the way reality is individuated intrinsically' can be read as a qualification, if 'success' is construed as correspondence between scheme and reality. Here is the translation: 'natural science has been successful, which is just to say that its individuation schemes correspond to the way reality is individuated intrinsically.' However, 'success' cannot be so defined without begging the central question. Imagine this were the argument:

Premise 1: The measure of success for a practice is correspondence between its individuation schemes and the way reality is individuated intrinsically.

Premise 2: The natural sciences have been successful.

Conclusion: The individuation schemes of the natural sciences correspond to the way reality is individuated intrinsically.

This appears to be a deductive argument. If the premises are true, and 'success' is being used consistently, then the conclusion seems to follow necessarily. However, the premises are dubious since they assume that science has been successful in the sense that needs to be shown.

An alternative formulation of the argument from success is inferential and involves a different definition of success. This improved argument is that the natural sciences have been successful at prediction, control, and contribution to technological advancement, because their individuation schemes correspond to the way reality is individuated intrinsically. In this argument, the clause after the 'because' does not appear to be a qualification of the clause before the 'because'. In other words, the presumed explanans does not appear to be a mere paraphrase of the presumed explanandum, which suggests that the argument is at least a valid abductive inference. Here is the improved argument schematized: 
Premise: The natural sciences have been increasingly successful at prediction, control, and contribution to technological advancement.

[Implicit question: what explains the premise?]

Conclusion: The individuation schemes of the natural sciences correspond to the way reality is individuated intrinsically.

\section{Assessing the Abductive Inference}

The conclusion of the abductive inference schematized above is that reality is individuated intrinsically and it is as the natural sciences describe it. The argument does not merely conclude along with Scientific Realism that the entities referred to and postulated by the natural sciences exist. Individuative Realism is stronger than Scientific Realism (so construed), since Individuative Realism requires not just that certain individual entities and/or kinds of entities exist, but that they are circumscribed by boundaries that are totally independent of our gerrymandering. The key distinction here is between things that exist and things that have boundaries that inhere in nature independent of where we draw the lines. For instance, mountains exist, but they do not have inherently natural boundaries. The same goes for the stripes of a rainbow. The point is that if the abductive inference from the success of science cannot support Scientific Realism, it certainly cannot support the more stringent Individuative Realism. Many unobservable scientific postulates that were (and perhaps still are) explanatorily efficacious, such as the bodily humors, phlogiston, the physiological vital force, and electromagnetic and optical ethers, turned out not to exist after all. ${ }^{17}$ Though as Larry Laudan concludes, "a theory's success is no warrant for the claim that all or most of its central terms refer" ${ }^{18}$ it of course does not follow that no scientific terms refer.

Now the crucial question: Could a correspondence between the individuation schemes of science and the way reality is individuated intrinsically explain the success of science? The abductive inference.

${ }^{17}$ Larry Laudan, "A Confutation of Convergent Realism", in Scientific Realism, edited by Jarett Leplin (Berkeley, CA: University of California Press, 1984), p. 231.

${ }^{18}$ Laudan, "A Confutation of Convergent Realism", p. 244. 
is initially plausible. Accurate descriptions are often major factors in the success of an endeavor. For instance, getting from point $A$ to point $B$ is often expedited with an accurate map. Imagine that a driver had always relied exclusively on verbal directions gleaned at gas stations en route to far and remote destinations. He would occasionally proceed in the wrong direction, confuse memorized directions, forget crucial details, and generally travel inefficiently. Imagine now that he starts using accurate and detailed road maps and attains his destinations far faster than before, while reducing expenses on gas, food, and accommodations. What would account for his newfound success? His use of the maps. All things equal, this fact would explain his more efficient travel.

The abductive inference in support of Individuative Realism is similar, except that something is inferred to explain something else. That scientists have an accurate map (what is inferred) could go a long way toward explaining their success. A significant disanalogy involves the terrain. In the driving case, the terrain is primarily roads and significant landmarks. A map's accuracy can be verified by comparison with the terrain. In the case of Individuative Realism, it is not antecedently known whether reality has its own inherent individuation scheme to which the individuation schemes of science can be compared. It is both (1) a correspondence to (2) the way reality is individuated intrinsically, that is inferred. The strength of the inference depends on its ability to explain the success of science; and there is reason to think it can do so only weakly.

The driving example can help demonstrate that possessing an accurate map, either of roads or the way reality is individuated intrinsically, would not reliably explain success. A could reliably be inferred from an occurrence of $B$, if $A$ is a necessary condition of $B$. $A$ could less reliably be inferred from an occurrence of $B$, if $A$ is only a sufficient condition for $B$. However, in the driving example, having an accurate road map is neither a necessary nor a sufficient condition for attaining the destination. It is not a necessary condition, because the destination can be attained without an accurate map, and it is not a sufficient condition, because having an accurate map does not guarantee attainment of the destination. There are only certain cases in which attaining one's destination is caused and thus explained by using an accurate map. 
Analogously, if a correspondence between the individuation schemes of science and the way reality is individuated intrinsically is neither a necessary nor a sufficient condition for the success of science, then it is not necessarily the case that such a correspondence would explain the success of science. First, is such a correspondence a necessary condition for the success of science? If it is true that central terms of successful scientific theories have not referred to anything real, then an isomorphism between the schemes of science and reality is evidently not a necessary condition for the success of science. Second, is such a correspondence a sufficient condition for the success of science? A negative answer can be supported by analogy to the driving example. Were a road map perfectly accurate, it would have to be incredibly detailed. Not only would it have to represent the useful details, such as roads, major topographical formations, and towns, but all details, including the precise locations of blades of grass, pebbles, and insects. That the latter details are not in our interest is irrelevant, since what matters is that the map be perfectly accurate. Were the map, like most road maps, printed on paper, then it would be large, perhaps even as large as the reality it depicts. Would having such a perfectly accurate map be a sufficient condition for-that is, would it guarantee-success, which in the driving case entails attaining the destination in a timely manner? Probably not, and the enormity and complexity of the map would be a likely cause of failure. In order for a map to be useful, it has to be imperfect, depicting only certain features of reality-and those in only minimal detail-that conduce to our interest in getting around.

Could an individuation scheme that cuts reality at its inherent joints also be of limited use, if not downright encumbering, for scientists? The answer of course depends on how reality is actually individuated. If the inference is true that reality is intrinsically individuated in the way science individuates it, then the answer is evidently no. However, if the way in which reality is individuated intrinsically is extremely complex, then a perfectly accurate map of it could conceivably, as in the driving case, be of limited use. The point is that a correspondence between scheme and reality is not necessarily a sufficient condition for scientific success. Couple this with the conclusion that such a correspondence is not a necessary condition for scientific success, and it seems that a correspondence between scheme 
and reality.is not obviously the best or even a viable explanation of the success of science.

A major hurdle for the abductive inference from the success of science is making the causal connection between success and correspondence. I have argued that a correspondence between the individuation schemes of science and the way reality is individuated intrinsically could not obviously explain the success of science. But let us give Individuative Realism the benefit of the doubt and assume for the sake of argument that a correspondence between scheme and reality could explain the success of science. Now the question is this: If a correspondence between scheme and reality could explain the success of science, would reliable knowledge about the way reality is individuated intrinsically be in the offing? In other words, would explanatory efficacy in this case yield truth? One reason to think not is that explanatory efficacy is itself not, especially in the history of science, a reliable indicator of truth. Many unobservable entities inferred by scientific theory, which were explanatorily powerful, did not exist. Following Arthur Fine, since abductive inference has been unreliable on a case by case basis in the history of science, it is unreasonable to think it would be any more reliable in extremely general cases, such as the case of Individuative Realism. ${ }^{19}$

\section{Conclusion to Part B}

Part B examined an abductive inference in support of Individuative Realism. The argument is that an inferred correspondence [between (1) the individuation schemes of the natural sciences and (2) the also inferred way reality is individuated intrinsically] could explain the success of science. There are two major problems with this argument. First, it does not seem that such a correspondence could readily explain the success of science, since such a correspondence seems neither to be a necessary nor a sufficient condition for the success of science. Second, even if such a correspondence could readily explain the success of science, there is reason to think that explanatory efficacy is not a reliable indicator of truth in the relevant domain.

${ }^{19}$ Arthur Fine, "The Natural Ontological Attitude", in The Philosophy of Science, edited by Richard Boyd, Philip Gasper, and J. D. Trout (Cambridge, MA: The MIT Press, 1991). See especially pp. 262-263. 


\section{Part C: Confirmability and Simplicity}

\section{Confirmation}

A third indirect strategy for Individuative Realism involves disconfirming the wrong individuation schemes and confirming the right schemes by repeated empirical observation. As an illustration of how this is supposed to work, imagine that a portion of reality appears like the following $9 \times 9$ grid:

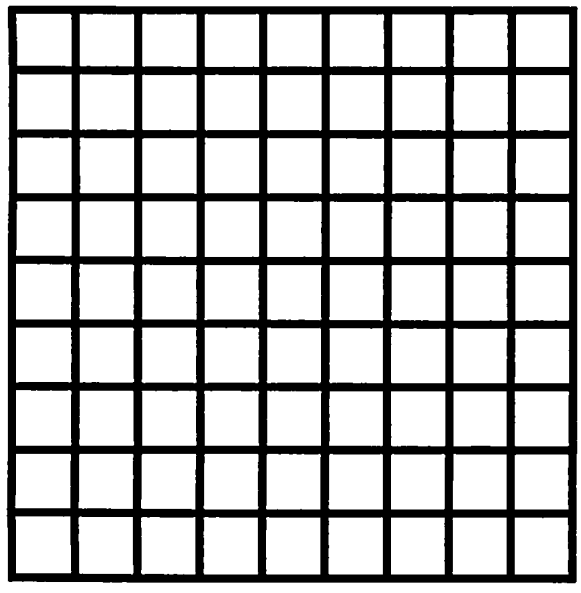

Figure 1: A Hypothetical Section of Reality

The pressing question for the Individuative Realist is how this area is individuated intrinsically. In other words, what are the boundaries that matter intrinsically? The obvious answer is that the intrinsically important boundaries are the ones demarcating the 81 squares, though there are many less obvious boundaries. The grid could be divided horizontally, vertically, or diagonally in half. Additionally, each of the 81 squares could themselves be divided in these ways. And so on ad infinitum. How could it be determined which of these boundaries are intrinsically important? One way of determining this is by observing what actually transpires in the region-by observing how things interact and interrelate.

Entertain the following story about our hypothetical world. One day to the surprise of scientists and laymen alike, a few things appeared on the previously blank grid in rapid succession. The end result is depicted in the following figure: 


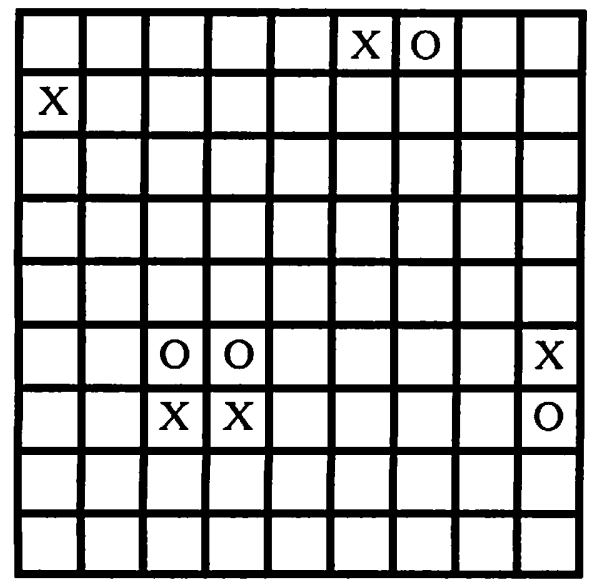

Figure 2: First Observation

Proponents of the 81-square scheme took the observation as confirmation of their theory that the region is individuated intrinsically into the 81 visible squares. Incidentally, they also thought the appearance of nine letters was significant, since nine squared is 81 . Other scientists interpreted the observations as evidence that the grid is ultimately divided into 'square pairs', each comprised of two adjacent squares and each containing an $\mathrm{X} / \mathrm{O}$ pair. However, they were at a loss to account for the anomalous single $X$ in the upper left of the grid.

Then, without warning, the $\mathrm{Xs}$ and $\mathrm{Os}$ were suddenly rearranged, as follows:

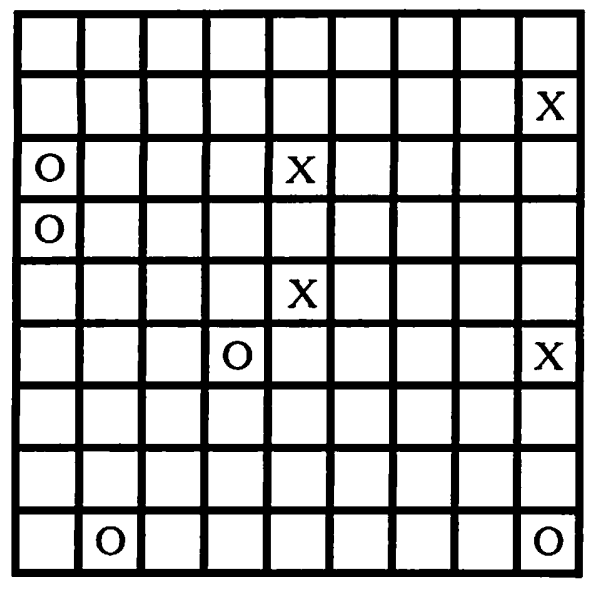


Unlike the first time, after the Xs and Os appeared in place, a strange phenomenon occurred: a line, characterized by some observers as a lightning bolt, flashed through and connected the three Os on the left side of the grid. Scientists took this second arrangement of Xs and Os to be disconfirming evidence for the 'square pair' scheme, since only two of the letters were adjacent this time, and they were not even an $\mathrm{X} / \mathrm{O}$ pair, as they all had been before. Though the proponents of the 81-square scheme felt their scheme had been further confirmed, they could not account for the linear flash.

Around this time an article in a leading science journal reported a pattern observed in both events. Though the Xs and Os had appeared in rapid succession, in both events they alternated. Upon hearing this, the scientist, whose fame was at that moment forged, exclaimed: "Oh my God ... it's tic-tac-toe!" Sure enough, the data from the two observations, and every observation thereafter (trust me), confirmed the theory. Superimposing the true grid lines onto the observed arrangements makes it clear that tic-tac-toe was indeed the name of the game:
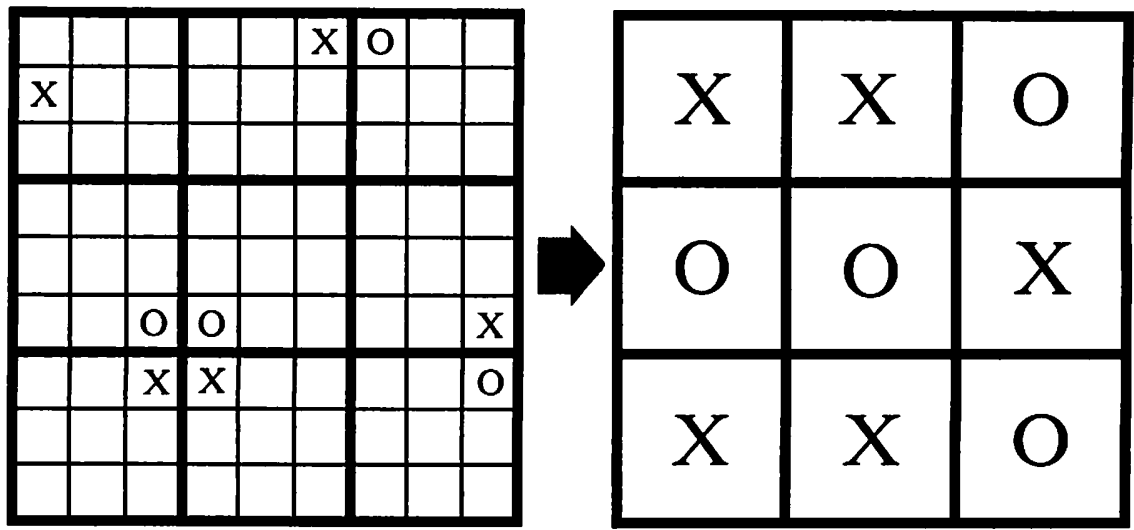

Figure 4: First Observation Converted to True Scheme

Though it initially seemed that the borders around all 81 squares were important, in part because the $\mathrm{Xs}$ and $\mathrm{Os}$ appeared within those borders, it turned out that only the borders around the 9 squares in bold in the converted grids above really mattered. Thereby, through observation and analysis, the rival individuation schemes were disconfirmed, and the $3 \times 3$ scheme confirmed. 

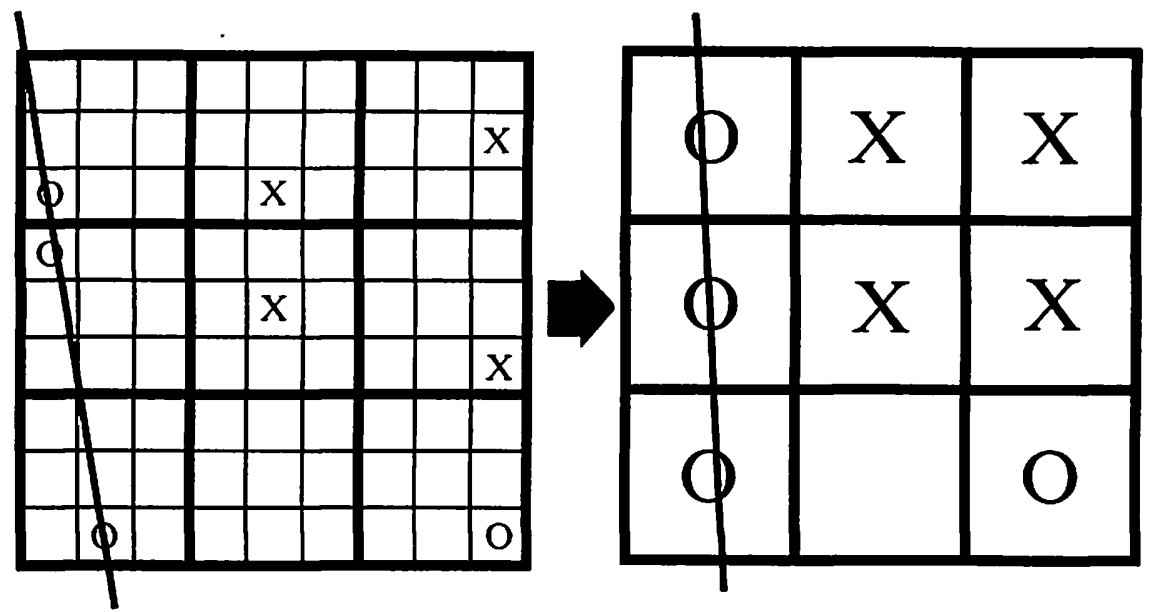

Figure 5: Second Observation Converted to True Scheme

The point of the tic-tac-toe example is to show how the correctness of an individuation scheme can be confirmed by repeated empirical observation-how repeated empirical observation can confirm which boundaries are intrinsically real, and disconfirm the rest. But the deck is stacked in favor of Individuative Realism in this example. Whereas the purpose of tic-tac-toe is known antecedently, the purpose of natural displays, such as observed phenomena in outer space, is not. In addition, the rules of tic-tac-toe were devised by people, whereas the laws of nature were not. Thereby, in this particular example, we might be confusing the borders that matter to us with the borders that matter intrinsically-and the Individuative Realist is solely concerned with the latter. So perhaps a good shuffle of the deck can yield an example which avoids these biases.

\section{Confirmation and Underdetermination}

Consider the following ways of individuating a particular hunk of reality. The first individuation scheme (IS1) includes the following three individuals: the earth, moon, and sun. The second (IS2) includes six individuals: earthhalf1, earthhalf2, moonhalf1, moonhalf2, sunhalf1, and sunhalf2, where earthhalf 1 and earthhalf 2 jointly comprise what we call the earth, and so on. The third (IS3) includes two individuals, the earth and the moonandsun, the latter of which is a single object jointly comprised of what we separately call the moon 
and the sun. These are different ways of individuating reality. Now, can empirical observation confirm that one of these individuation schemes cuts reality at its inherent joints, or disconfirm at least one of the others?

Consider the observation of a lunar eclipse where, in the lingo of IS 1 , the earth passes between the moon and the sun, thereby shading the moon. Evidently this observation can be expressed in IS1, but can it be expressed in IS2 and/or IS3 without signifying the individuals of IS1? The answer is affirmative for IS2: when earthhalf1 and earthhalf2 jointly pass between the conjunction of sunhalf 1 and sunhalf 2 and the conjunction of moonhalf 1 and moonhalf2, an eclipse of moonhalf1 and moonhalf2 is observed. Now how about IS3? It is questionable whether the lunar eclipse is expressible in the idiom of IS3, because describing and explaining the eclipse requires distinguishing between what we call the sun and moon, but they are conflated in IS3. More specifically, in order to describe the eclipse, the earth has to be described as passing between things. However, in IS3 there are not multiple things between which the earth can pass, only the single object 'moonandsun'. This is perhaps a manageable obstacle for IS3, since single things (such as basketballs and footballs) can pass through other single things (such as hoops and goal posts). For the sake of argument, assume that the moonandsun is such that the earth can pass through it. Even with this concession a distinction is still required between two parts of the hoop, the fluorescent (sun) part and the shaded (moon) part. Though this may not decisively disconfirm IS3, one suspects that some individuation schemes would be disconfirmed by the observation of a lunar eclipse-perhaps an individuation scheme that made no distinction between the earth, moon, or sun.

Regardless of which if any schemes are disconfirmed, the important point is that both IS1 and IS2 seem equally well-confirmed by the data. More importantly, there are indefinitely more individuation schemes that, like IS2, subdivide the earth, moon, and sun in finer and finer ways. Consequently, any observation that confirms IS2 will also confirm all the other individuation schemes that, like IS2, acknowledge the macro-level distinction between the earth, moon, and sun, but further subdivide each. This is an instance of the underdetermination of theory by data-the rival theories being rival 
individuation schemes. Empirical observation cannot adjudicate decisively between these many rival individuation schemes, since (so the story goes) any observation that confirms one scheme will also confirm the finer permutations of that scheme.

The underdetermination of individuation schemes, if valid, puts us right back where we started, with many individuation schemes and no independent criterion for determining which cuts reality at its inherent joints. Criteria such as being determined by natural properties, explanatory efficacy, and confirmability seem insufficient. Are there any others?

\section{Simplicity}

A possible criterion for determining which of two equally wellconfirmed individuation schemes gets reality right is simplicity. In the eclipse example, (IS1) the scheme that individuates reality into the earth, moon, and sun is more intuitively simple than (IS2) the scheme that individuates reality into moonhalf1, moonhalf2, earthhalf1, earthhalf2, sunhalf1, and sunhalf2. (IS1) is prima facie simpler than (IS2), in part because the former scheme is familiar, but also because the former scheme is more ontologically parsimonious: it employs three objects rather than six.

The claim that simplicity (as ontological parsimony) favors familiar individuation schemes can, however, be challenged by a cleverly chosen example. Consider an individuation scheme (IS4) that recognizes two individuals: the moonsun and the earthsun. ${ }^{20}$ The moonsun is an object that is either the moon or the sun, and the earthsun is an object that is either the earth or the sun. The lunar eclipse can be described using only these 'individuals' as follows: when the earthsun that is not the moonsun passes directly between (1) that which is shared by the earthsun and the moonsun and (2) the moonsun that is not the earthsun, an eclipse is observed. It thereby seems that this bizarre individuation scheme is confirmed, or at least not disconfirmed, by the eclipse. Now to the point. The salient feature of this

${ }^{20}$ This example and its intended force is inspired by a kindred example in Eli Hirsch, Dividing Reality (New York: Oxford University Press, 1993), pp. 8081. Sophie R. Allen also discusses Hirsch's example in "Deepening the Controversy over Metaphysical Realism", Philosophy 77 (October 2002), pp. 525-526. 
bizarre individuation scheme is that it requires only two 'individuals' (the moonsun and the earthsun), while the familiar scheme employs three individuals (the moon, earth, and sun), thereby making the former more ontologically parsimonious than the latter.

Or is it? It is worth considering that the individuation scheme comprised of the moonsun and earthsun is an illegitimate individuation scheme. The familiar individuation scheme comprised of the earth, moon, and sun individuates reality by dividing reality into three discrete individuals. The individuation scheme comprised of moonhalf1, moonhalf2, earthhalf1, earthhalf2, sunhalf1, and sunhalf 2 also individuates reality into what are, at least upon reflection, fairly discrete individuals. Were the earth divided in two, the resulting halves could conceivably be distinct, non-overlapping individuals. However, the earthsun (the object comprised of the earth or the sun) and the moonsun (the object comprised of the moon or the sun) are not discrete, individual objects in anything approaching the ordinary sense of the word 'individual'.

Even if familiar individuation schemes are also the simplest (in terms of ontological parsimony), their qualifications for matching the way reality is individuated intrinsically would be no more evident, since there is no obvious reason to presume that ontological parsimony is an indicator of inherence. In virtue of what does the ontological parsimony of an individuation scheme entail that it cuts reality at its inherent joints? It seems that once again the desideratum is a decisive, albeit elusive, independent criterion. Furthermore, regardless of how 'simplicity' is construed, it seems ineligible as an indicator of inherence, since its being so would make inherence a function of something about us-namely, what we find simple. And the way reality is individuated intrinsically-as long as the notion 'intrinsic' is taken seriously-is supposed to be totally independent of anything about us. ${ }^{21}$

\section{Underdetermination Undermined?}

Thus far, it has been entertained that many individuation schemes are equally well-confirmed by the data-in other words,

${ }^{21}$ Elgin makes this point regarding natural properties in "Unnatural Science", pp. 292-293. 
that individuation schemes are underdetermined by the data. I now want to raise an objection to the underdetermination thesis as it relates to Individuative Realism. Though it may be the case in theory that theories are underdetermined by the data, this is not always true in practice. Consider the following illustration. At the Grand Teton Climber's Ranch, you notice that Jim and Ryan have a vast array of climbing and camping gear spread out and are carefully packing two enormous backpacks. They are wearing mountaineering boots, chugging water, and applying gobs of sunscreen. You inquire about their activity and Jim casts his gaze toward the granite peaks high above. Based on this data, you infer that they are momentarily embarking on a multi-day mountaineering excursion, though you are unable to speculate about their trail of ascent, base camp location, or climbing itinerary. Your theory about their impending trip is thereby underdetermined by the available data. Such underdetermination is irrelevant for your purposes, though. Since you were intending to invite Jim and Ryan to dinner, their imminent departure rules out their dining with you, which is all you need to know. The preceding example generalizes. The underdetermination of theory is often inconsequential, because for our purposes we need details, but not every detail. As long as a theory provides sufficient detail, then its being underdetermined, and hence compatible with an array of theories varying on insignificant details, is irrelevant. Now the question: Is the alleged underdetermination of individuation schemes irrelevant to Individuative Realism as well?

The important point raised above is that for our interests and purposes the underdetermination of theory is often irrelevant. However, our interests and purposes cannot be deciding factors in determining how reality is individuated intrinsically. The Individuative Realist aims to find reality's inherent joints; as inherent, the location of these joints has to be totally independent of - not in any way a function of-our interests and purposes. It cannot be for Individuative Realism, as it is in more mundane pursuits, that our interests and purposes determine which level of detail in a theory (or in this case, an individuation scheme) is sufficient, thereby rendering vast numbers of subtle permutations of theory irrelevant. 
Conclusion to Part $C$

The confirmation of individuation schemes by empirical observation appears inadequate for determining how reality is individuated intrinsically, since the same empirical observations confirm many individuation schemes - that is, individuation schemes are underdetermined by the data. Simplicity is not a viable criterion for finding the one right individuation scheme either, since simplicity is a function of our interests and purposes, which are precisely what needs to be factored out of the equation (so long as the notion 'intrinsic' is taken seriously). Finally, though in practice the underdetermination of theory is often inconsequential, since the many permutations on a general theory are irrelevant to our interests and purposes, this exemption does not apply for Individuative Realism, since the way reality is individuated intrinsically cannot depend on anthropocentric factors (again, so long as the notion 'intrinsic' is taken seriously).

\section{Part D: Conclusion}

In the introduction, I suggested that the challenge faced by Individuative Realism is analogous to finding a key that matches a particular keyhole. A match cannot be determined 'directly' by simply comparing or otherwise visually inspecting the key and keyhole. Rather, a match must be determined 'indirectly' by something other than direct observation-namely, the unlatching of the lock. The unlatching of the lock is an independent criterion for determining a match between key and keyhole. This paper critically considered several such independent criteria for determining a match between our individuation schemes and the way reality is individuated intrinsically, including the individuation scheme's being (1) a function of natural properties, (2) able to explain the success of science, (3) confirmed by empirical observation, and (4) simple. Though each of these strategies was reviewed unfavorably, there are probably ways of construing or tweaking them that could get around the specific. objections raised in this paper. Such ancillary debates could probably go on forever. I suspect that real progress in the debate can instead be made by considering the general strategy under which the particular strategies are subsumed. 
There is reason to think that the general strategy of finding an independent criterion for determining which individuation schemes cut reality at its inherent joints is untenable. The reason for this can be understood by analogy to the key and keyhole case. In the key and keyhole case, we know antecedently (1) that there are keys, (2) that there is a keyhole, and (3) what happens when there is a match between key and keyhole (the lock opens). The only unknown is which key matches the keyhole. The situation for Individuative Realism is significantly different. We know that there are individuation schemes. However, we do not know (1) which individuation schemes cut reality at its inherent joints, (2) what happens when there is a match (the independent criterion), or even (3) that reality is individuated intrinsically. One known and three unknowns in an equation is a recipe for skepticism.

The challenge faced by the Individuative Realist can perhaps more profitably be understood by contrast with another mundane case. Imagine that we are trying to guess the length of a lobster just by looking at it. Everyone has a different guess. How do we determine who, if anyone, is right? By consulting an agreed upon standard of measurement, such as a ruler or caliper. It is here where things appear especially grim for the Individuative Realist. Consulting an agreed upon standard is not an option for the Individuative Realist, since that would make the purportedly intrinsic boundaries a function of something about us-namely, our agreement. Whereas in ordinary life it is perfectly acceptable that our objective standards are actually intersubjective-that is, a function of widespread agreement - in the case of Individuative Realism, an acceptable standard would have to be purely objective-that is, totally independent of our intersubjective conventions (so long as the notion 'intrinsic' is taken seriously). Thus it seems that the standard required by Individuative Realism is beyond our reach. And if so, then even if reality is individuated intrinsically, we cannot know how it is individuated intrinsically. ${ }^{22}$

${ }^{22}$ I would like to thank Eric Schwitzgebel and especially Peter Graham for many helpful comments and conversations about various drafts of this paper. 


\section{References}

Allen, Sophie R. "Deepening the Controversy over Metaphysical Realism". Philosophy 77 (October 2002).

Elgin, Catherine Z. "Unnatural Science." The Journal of Philosophy 92:6 (June 1995).

Fine, Arthur. "The Natural Ontological Attitude". In The Philosophy of Science. Edited by Richard Boyd, Philip Gasper, and J.D. Trout. Cambridge, MA: The MIT Press, 1991.

Hirsch, Eli. Dividing Reality. New York: Oxford University Press, 1993.

Laudan, Larry. "A Confutation of Convergent Realism". In Scientific Realism. Edited by Jarett Leplin. Berkeley, CA: University of California Press, 1984.

Lewis, David. "New Work for a Theory of Universals". Australasian Journal of Philosophy 61:4 (December 1983).

. "Putnam's Paradox". Australasian Journal of Philosophy 62:3 (September 1984).

McGowan, Mary Kate. "The Neglected Controversy Over Metaphysical Realism". Philosophy 77 (January 2002).

Page, Sam. "The Challenge of Observing Reality's Inherent Joints". Kriterion 20 (2006). 